\title{
DISEÑO, CONSTRUCCIÓN Y EVALUACIÓN DE UN SISTEMA DE CONTACTOR BIOLÓGICO ROTATORIO (CBR) PARA EL TRATAMIENTO DE AGUAS RESIDUALES MUNICIPALES A ESCALA PILOTO
}

Ivette Echeverría, Oliver Saavedra, Ramiro Escalera, Gustavo Heredia, Renato Montoya

\section{RESUMEN}

En este estudio se diseñó, implementó y evaluó el desempeño de una planta piloto de tratamiento de aguas residuales domésticas, basada en contactores biológicos rotatorios (CBR). La demanda de fuentes de agua en zonas semiáridas ocasiona que se reutilicen aguas residuales en agricultura, aunque no tengan ningún grado de tratamiento. Los CBR son sistemas de tratamiento aerobio llevado a cabo por microorganismos adheridos sobre discos que rotan lentamente a través de un flujo de agua residual. Entre las ventajas del sistema se puede mencionar, los niveles potencialmente altos de eficiencia, que ocupan poco espacio y se pueden ampliar modularmente; sin embargo, son sistemas costosos de implementar, debido a que se requiere de la importación de los discos. En este estudio se escogió el poliestireno por su disponibilidad local y se verificó que es un medio de adherencia adecuado para los microorganismos. Las eficiencias máximas alcanzadas por el CBR una vez concluido el periodo de aclimatación fueron: $81 \%, 75 \%$ y $85 \%$ para la remoción de DQO total, DQO soluble y SST. La eficiencia global del sistema constituido por un sedimentador primario, un CBR de 3 etapas y un sedimentador secundario, alcanzó niveles de 6879\% para DQO total, 68-77\% de DQO soluble y 81-99\% de SST. Los niveles de tratamiento alcanzan valores dentro de los límites establecidos en la legislación boliviana para descarga de aguas residuales, por lo que es recomendable su escalamiento en condiciones climáticas similares a las del estudio.

Palabras Clave: CBR, Eficiencia, Piloto, Agua Residual, PTAR Compacta, Tratamiento Aerobio, Bolivia.

DOI: 10.23881 idupbo.020.1-3i 